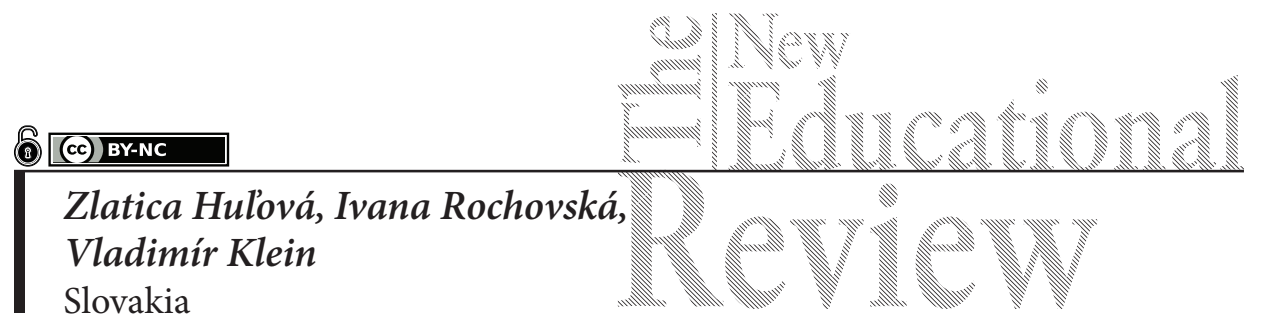

\title{
The Issue of Age Homogeneity in Groups from the Kindergarten Teacher's Perspective
}

DOI: 10.15804/tner.2018.53.3.17

\begin{abstract}
The aim of our study was to find out how kindergarten teachers perceive the issue of age-homogeneous and heterogeneous classes at kindergartens. A self-designed questionnaire and interview were used for measuring, which was part of the research methods used (interview, observation, questionnaire). The questionnaire included items aimed at finding out respondents' opinions on the age composition of children in kindergarten classes. The research sample consisted of 234 female teachers. On the basis of results it can be stated that respondents preferred age-homogeneous groups in classes. However, those teaching age-heterogeneous classes saw more advantages of such division. Research results also showed that younger respondents preferred dividing children into age-homogeneous groups more than older respondents.
\end{abstract}

Keywords: pre-primary education, kindergarten, age-homogeneous groups, age-heterogeneous groups

\section{Introduction}

The aim of pre-primary education is to contribute to the development of the child's personality along with the family environment, in the cognitive, sensorimotor, social and emotional aspect. It prepares the child for entry into further levels of education, but also for life in society. European and developed countries endeavour to respond to current trends in pre-primary education (Early 
Childhood Education and Care Systems in Europe, 2015). In terms of integration of children into kindergartens, inclusive education is the trend, supporting the heterogeneity and development of the child's personality without comparison with other children. ${ }^{1}$ In Slovakia, too, the interactionist approach (against more extreme approaches of empiricism or nativism) is stressed in preparation of current curricular documents for pre-primary education; what is preferred is the democratic style, mutual respect and trust, and partner communication. The adult is not the one who knows and the child the one who should learn from him/ her, but the adult plays the role of the child's facilitator and partner, they share activities, gain experience, which is the groundwork for acquisition of knowledge, skills, experience, attitudes, values, etc.

Also, in terms of pre-primary education organization, there are efforts to respond to the latest research findings and many experts (e.g., Gray, 1997, 2004, 2008, 2013; Greenberg, 1992; Neill, 1995; Montessori, 2004 and others) propose formation of age-heterogeneous groups.

\section{Theoretical background of the issue studied}

Formation of age-heterogeneous groups at kindergartens is no innovation in Slovakia. It was commonly applied already before 1948. Later kindergarten started to divide children into classes by age, and even when composed heterogeneously (e.g., at rural kindergartens), activities for individual age categories were planned separately.

The Decree of the Ministry of Education of the Slovak Republic of 15 July, 2009, amending the Decree No.306/2008 Coll. of the Ministry of Education of the Slovak Republic on kindergartens, makes it possible in Slovakia to form age-homogeneous as well as age-heterogeneous classes. Children in age-homogeneous classes are organized in groups similarly as at elementary school (e.g., 5-6-yearold children). In age-heterogeneous classes, children of various ages are mixed. They are sometimes single-class kindergartens, sometimes family-type schools respecting also family relations or friendships among children and their families.

${ }^{1}$ Inclusive education means that everybody has access to good education while education is meant as the development of all personality facets, not only cognition. Inclusive education at kindergartens and elementary schools has been dealt with, e.g., in the following publications: A guide for ensuring inclusion and equity in education, 2013; School for all, 2017; Kaleja, 2016; Blyznyuk, Sydoriv, 2017; Vančíková, Porubský, Kosová, 2017, and others. 
US psychologist P. Gray (2008) dealt with the issue of self-education (in children of hunters and gatherers in primitive tribes) and arrived at the conclusion that education of children was more effective when children were in age-heterogeneous groups. The author also quoted D. Greenberg (1992), according to whom free age mixing is the key to self-education. Together with J. Feldman, P. Gray (1997) carried out research into interactions of pupils in age-heterogeneous groups at school in Sudbury Valley. During the research, the school was attended by approximately 200 pupils aged 4 to 18 ; they were free to move and establish contacts. The authors found out that more than $50 \%$ of interactions happened among the pupils over two years of age and $25 \%$ of interactions were among the pupils with the age difference of more than 4 years. Their explanation of the fact was that helped by older children, younger children could play games or carry out activities that were in the zone of their proximal development (Vygotsky, 1956). P. Gray (2013) adds that while educators use Vygotsky's concept mainly to describe interactions between teachers and children, it could relate even more to natural interactions among children of various ages, i.e., between younger and older children.

These studies (Gray, Feldman, 1997, 2004) revealed several advantages of age-heterogeneous groups. Younger children have the opportunity to learn through activities they could not do alone or with children of the same age. Children are more attracted by free games in age-heterogeneous groups than by games with peers. They are less focused on competition, more creative and help more to exercise new skills. Younger children want to do what the older ones do, considering them good helpers and advisors (they do not help or advise them too much), good teachers (they are not too far ahead of them, e.g., in knowledge, skills). Older children expand their own knowledge by explanations to younger children while developing empathy and nurturing skills.

In addition to numerous advantages, the age-heterogeneous composition of children in groups has also its disadvantages. For instance, according to Matejcek (2015), child development stages are specific, thus children of different ages have different needs. Besides, children can be divided into age-heterogeneous groups particularly in the conditions where the optimum number of children in class is not exceeded and the group of the youngest children requiring the most care from the teacher does not prevail. With age-heterogeneous composition of children, education cannot be oriented on performance and children's experiences must be preferred to the resulting products of activities. Younger children must not be under-appreciated, older children must not be over-appreciated; the teacher must educate children in the spirit of partnership, mutual respect, trust and help. Also, from the point of view of the teacher, work in age-heterogeneous groups is more 
demanding in terms of preparation and organization. Finally, it could be mentioned that work in age-heterogeneous classes (the same as in age-homogeneous classes) is made easier by rules.

\section{Research problem}

The issue of the division of children into kindergarten classes by age is considered to be of current interest because pre-primary education teachers' opinions on the age homogeneity of groups differ from the opinions of the prevailing number of professionals supporting division of children into age-heterogeneous groups. Teachers accept such division mainly because it concerns single-class kindergartens, where the number of children does not allow for forming groups by age. However, they perceive children in terms of "younger" and "older".' The above thoughts were our incentive for carrying out research into teachers' opinions on the issue. The research problem was the question, how kindergarten teachers perceived the issue of age-homogeneous and heterogeneous groups in kindergarten classes.

\section{Research aims and hypotheses}

The main goal of our research was to find out opinions of kindergarten teachers on age composition of groups in classes. The following objectives emerged from the main goal:

1) Find out whether teachers prefer such composition of groups in terms of homogeneity as they teach at present.

2) Find out what advantages and disadvantages teachers see in the division of children into age-homogeneous and heterogeneous classes.

3) Find out whether teachers' preference for the option of an age-homogeneous or an age-heterogeneous group in a kindergarten class is influenced by teachers' age.

Based on the research objectives, hypotheses were formulated following from the analysis and literature overview of the issue studied (Gray, 2008, 2013, and others):

1) Within the number of respondents teaching classes with age-homogeneous composition of children, there would be a statistically significant difference between respondents preferring age-homogeneous groups and respondents preferring age-heterogeneous groups.

${ }^{2}$ Based on our observations of education in age-homogeneous and heterogeneous classes and interviews with kindergarten teachers. 
2) Within the number of respondents teaching classes with age-heterogeneous composition of children, there would be a statistically significant difference between respondents preferring age-homogeneous groups and respondents preferring age-heterogeneous groups.

3) There would be a statistically significant difference between respondents teaching age-homogeneous and age-heterogeneous classes, in the number of ticked advantages of age-homogeneous and age-heterogeneous composition of children.

4) There would be a statistically significant difference between teachers under 40 years of age and over 41 years of age in the preference for classes with age-homogeneous and age-heterogeneous composition of children.

\section{Research methods}

\section{Research tools and procedures}

To find out respondents' opinions, a questionnaire was used, pilot-tested on 20 respondents and amended based on their recommendations.

The questionnaire included 8 items and supplementing items concerning teachers' age, length of teaching experience, and the school where they were teaching. Respondents answered whether they were teaching a class with age-homogeneous or age-heterogeneous composition of children, which class they would have chosen to teach in, what advantages and disadvantages they saw in the above-mentioned division of children by age, or they had the option to write anything they liked to add in relation to the issue studied. ${ }^{3}$

To find out respondents' opinions, an interview was used in order to compare information obtained through the questionnaire. The interview was unstructured. 20 respondents expressed their opinions in their own words.

To statistically verify Hypothesis 1 and Hypothesis 2, the chi-square goodness of fit test was used, since it was comparison of one group and one variable within it. To test Hypothesis 3 and Hypothesis 4, Pearson's chi-square test of independence was used, since it was comparison of two groups in a nominal variable. Tables 2-5 present the frequencies found, Tables 4 and 5 also expected frequencies.

${ }^{3}$ Due to the limited extent of the contribution, only some items were evaluated, on the basis of which it was possible to statistically test the hypotheses made. The whole wording of the questionnaire is referenced in the List of References hereof. 


\section{Research sample}

The research sample was obtained by convenience sampling. Questionnaires were administered in three ways: a) in person, b) by electronic mail, c) online via Facebook groups Teachers at Kindergarten, Inspirations for Teachers at Kindergarten, Kindergarten Teachers. The return rate of the questionnaires administered in person was $100 \%$, by electronic mail $90 \%$. The return rate of the third case could not be determined since it was not possible to find out how many teachers opened the link to the website with the questionnaire.

The research involved 234 female respondents - kindergarten teachers, out of whom 34\% worked as senior employees, $21 \%$ of them had Attestation 1.5\% of them had Attestation 2. Out of the total number of respondents, $47.01 \%$ were teaching in urban and $51.71 \%$ in rural kindergartens, $1.28 \%$ gave other, unspecified answer. Out of the total number of respondents, 83.76 were teaching at state, $12.82 \%$ at private, and $2.56 \%$ at church kindergartens. In terms of age, the research sample showed characteristics presented in Table 1. Out of the total number of respondents, $40.17 \%$ were teaching a class with age-homogeneous composition of children, $58.12 \%$ with age-heterogeneous composition of children, and $1.71 \%$ of the respondents gave other, unspecified answer. Tables 2 and 3 present the respondents' preferences for groups at kindergarten in terms of homogeneity.

Table 1. Respondents' age

\begin{tabular}{llccccc}
\hline Age (years) & under 20 & $21-30$ & $31-40$ & $41-50$ & $51-60$ & over 60 \\
\hline \% resp. & 0.85 & 19.66 & 23.08 & 27.35 & 26.50 & 2.56 \\
\hline
\end{tabular}

\section{Analysis and interpretation of research results}

Hypothesis 1 assumed that within the number of respondents teaching a class with age-homogeneous composition of children, there would be a statistically significant difference between respondents preferring age-homogeneous groups and respondents preferring age-heterogeneous groups. The frequencies found are presented in Table 2.

Out of the total number of respondents, 95 reported teaching a class with age-homogeneous composition of children. Out of them, 93 would have chosen to continue teaching a class with such composition of children, two gave other 
Table 2. Preference for age-homogeneous groups in teachers teaching age-homogeneous groups

\begin{tabular}{cc}
\hline & Prefer homo \\
\hline Yes & 93 \\
\hline No & 2 \\
\hline
\end{tabular}

answers, thus no-one would have chosen to teach a class with age heterogeneous composition of children.

Table 3 makes it clear that Hypothesis 1 could be confirmed. The result of the chi-square goodness of fit test $\chi^{2}=87.168$ with one degree of freedom and statistical significance of $p=0.000$. The result allowed us to state that there was a statistically significant difference. The teachers of a class with age-homogeneous composition of children preferred age-homogeneous groups more. Thus, hypothesis $\mathrm{H}_{1}$ was confirmed at the $5 \%$ significance level.

Hypothesis 2 assumed that within the number of respondents teaching a class with age-heterogeneous composition of children, there would be a statistically significant difference between respondents preferring age-homogeneous groups and respondents preferring age-heterogeneous groups. The frequencies found are presented in Table 3.

Table 3. Preference of age-heterogeneous groups in teachers teaching age-heterogeneous groups

\begin{tabular}{cc}
\hline & Prefer hetero \\
\hline Yes & 57 \\
\hline No & 82 \\
\hline
\end{tabular}

Out of the total number of respondents, 139 reported teaching a class with age-heterogeneous composition of children. Out of them, 57 would have chosen to continue teaching a class with such composition of children, and 82 would have chosen to teach a class with age-homogeneous composition.

The result of the chi-square goodness of fit test $\chi^{2}=4.496$ with one degree of freedom and statistical significance of $\mathrm{p}=0.034$. The result allowed us to state that there was a statistically significant difference. The teachers of a class with age-heterogeneous composition of children preferred age-homogeneous groups more. Thus, hypothesis $\mathrm{H}_{2}$ was confirmed at the 5\% significance level. 
Hypothesis 3 assumed a statistically significant difference between respondents teaching age-homogeneous classes (95) and respondents teaching age-heterogeneous classes (136), in the number of ticked advantages of age-homogeneous and age-heterogeneous composition of children.

It follows from Graph 1 that the teachers teaching age-heterogeneous groups ticked more frequently as an advantage the option that children in such groups have better conditions for social, emotional and cognitive development. The teachers teaching age-homogeneous groups ticked more frequently as an advantage the option that children in age-heterogeneous groups have better conditions for social development and the class resembles the family environment more. There was no considerable difference between the respondents teaching classes with age-homogeneous and age-heterogeneous composition of children in the order of the most frequently ticked advantages.

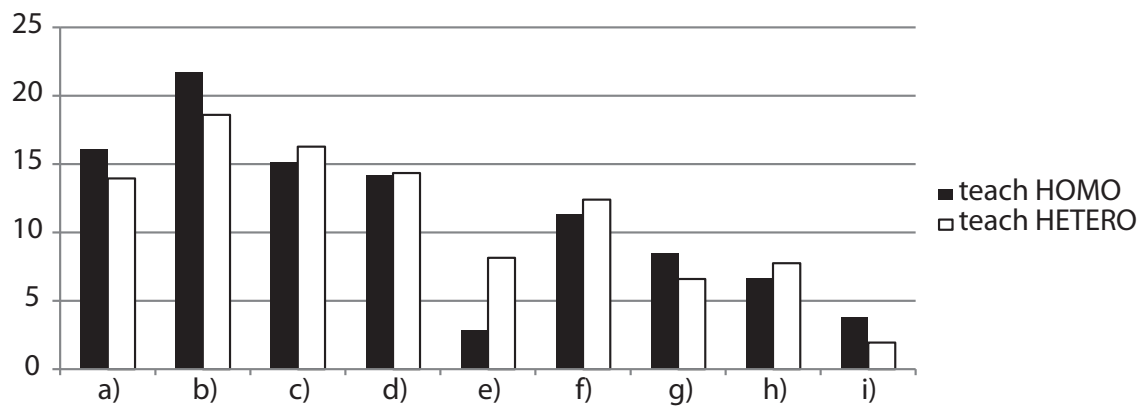

Graph 1. Advantages of kindergarten age-heterogeneous classes

Legend: teach HOMO - respondents teaching classes with age-homogeneous composition of children (in \%); teach HETERO - respondents teaching classes with age-heterogeneous composition of children (in \%); a) class resembles the family environment more; b) children have better conditions for social development; c) children have better conditions for emotional development; d) children have better conditions for cognitive development; e) competition among children is reduced; f) teacher can compare the progress a child has made for a longer time period; g) child creates a deeper relationship with the teacher; h) longer and better co-operation with a child's parents; i) other.

The respondents saw the greatest advantages of age-homogeneous classes in children having better conditions for cognitive development and in children of the same age understanding one another better. The respondents teaching age-heterogeneous classes saw an advantage of age-homogeneous groups also in the opportunity for children to compete with one another. 


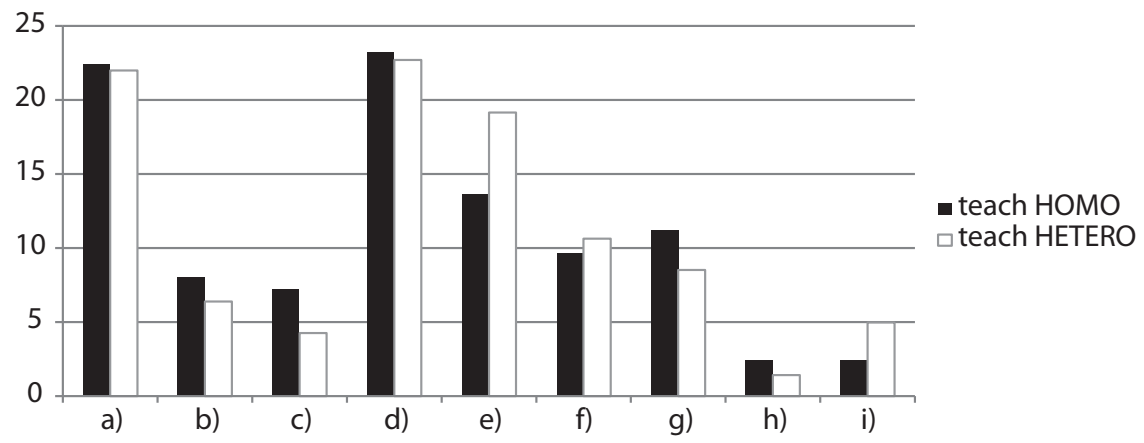

Graph 2. Advantages of kindergarten age-homogeneous classes

Legend: teach HOMO - respondents teaching classes with age-homogeneous composition of children (in \%); teach HETERO - respondents teaching classes with age-heterogeneous composition of children (in \%); a) children of the same age understand one another better; b) children have better conditions for social development; c) children have better conditions for emotional development; d) children have better conditions for cognitive development; e) children have the opportunity to compete with one another; f) child is evaluated by more teachers for more years; $g$ ) during kindergarten attendance for more years a child comes into contact with more teachers; $h$ ) child's parents come into contact with more teachers for more years; i) other.

The data about the number of advantages of age-homogeneous and age-heterogeneous groups given by the respondents are presented in the contingency table (Table 4).

Table 4. Advantages of age-heterogeneous groups from the point of view of respondents

\begin{tabular}{lccccc}
\hline & \multicolumn{2}{c}{ Actual frequency } & \multicolumn{2}{c}{ Expected frequency } \\
\hline & $\begin{array}{c}\text { Advantages } \\
\text { homo }\end{array}$ & $\begin{array}{c}\text { Advantages } \\
\text { hetero }\end{array}$ & $\begin{array}{c}\text { Advantages } \\
\text { homo }\end{array}$ & $\begin{array}{c}\text { Advantages } \\
\text { hetero }\end{array}$ \\
\hline Teach homo & 212 & 250 & Teach homo & 266.93 & 195.07 \\
\hline Teach hetero & 516 & 282 & Teach hetero & 461.07 & 336.93 \\
\hline
\end{tabular}

To evaluate the data, Pearson's chi-square test of independence was used. Its result $\chi^{2}=42.276$ with one degree of freedom and statistical significance $p=0.000$. The result allowed us to state that there was a statistically significant difference, thus the respondents teaching age-heterogeneous classes saw more advantages of such division. Thus, hypothesis $\mathrm{H}_{3}$ was confirmed at the $5 \%$ significance level. 
Hypothesis 4 assumed a statistically significant difference between teachers under 40 years of age and over 41 years of age in the preference for classes with age-homogeneous and age-heterogeneous composition of children. Graph 3 presents age categories of the respondents and their preference for an age-homogeneous or an age-heterogeneous class.

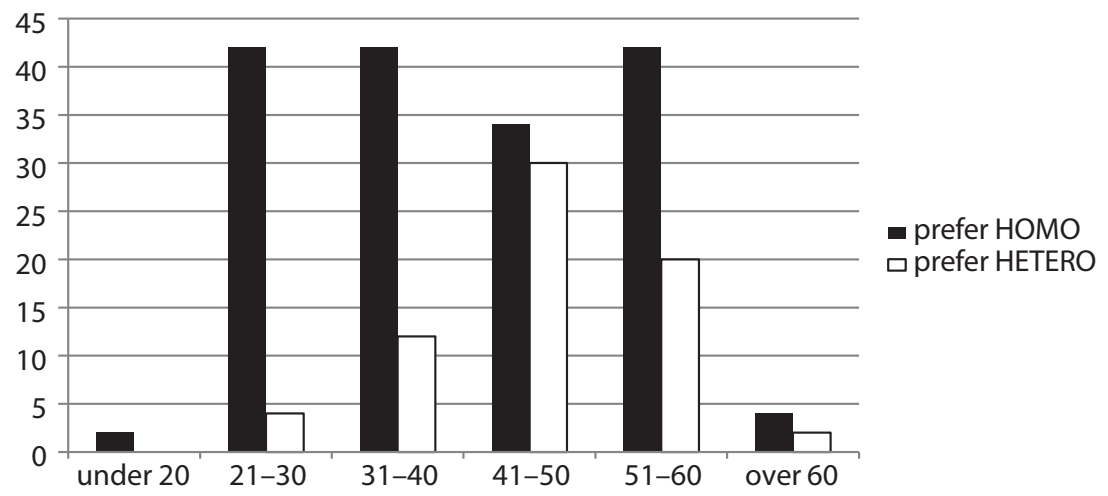

Graph 3. Preference for age composition of children in kindergarten classes by older and younger respondents

Legend: prefer HOMO - Number of respondents who would have chosen to teach a class with age-homogeneous composition of children; prefer HETERO - Number of respondents who would have chosen to teach a class with age-heterogeneous composition of children.

Graph 3 shows that a much higher number of teachers under 40 years of age preferred age-homogeneous groups. The teachers over 41 years of age still preferred age-homogeneous groups. However, the difference is less obvious.

Data about preference for age-homogeneous and age-heterogeneous classes by the respondents' age of are presented in the contingency table (Table 5).

Pearson's chi-square test of independence was used for calculation. Its result $\chi^{2}=15.6874$ with one degree of freedom and statistical significance $p=0.000$. The result allowed us to state that there was a statistically significant difference, thus the younger respondents preferred division of children into age-homogeneous groups more than older respondents. Thus, hypothesis $\mathrm{H}_{4}$ was confirmed at the $5 \%$ significance level.

The respondents who were interviewed expressed their opinions on the issue of age homogeneity in groups. There were three main groups of opinions: 1 . the respondents considered work with age-homogeneous groups easier. The main 
Table 5. Preference for age-homogeneous and age-heterogeneous classes by older and younger respondents

\begin{tabular}{lcclcc}
\hline & \multicolumn{2}{c}{ Actual frequency } & & \multicolumn{2}{c}{ Expected frequency } \\
\hline & Prefer homo & Prefer hetero & & Prefer homo & Prefer hetero \\
\hline Older & 80 & 52 & Older & 96.64 & 38.36 \\
\hline Younger & 86 & 16 & Younger & 72.36 & 29.64 \\
\hline
\end{tabular}

reasons were that younger children were not able to solve the tasks for older children; 2 . The respondents believed that in age-homogeneous groups it was better to teach one group during the whole attendance to kindergarten; 3 . The respondents considered work with age-heterogeneous groups good for the social and emotional development of the child.

\section{Discussion}

Based on our research results ${ }^{4}$ it was confirmed that the respondents preferred age-homogeneous groups, regardless of the class they were teaching. They believed that in such classes children's cognitive development is better, that they understand one another better. The respondents teaching classes with heterogeneous composition of children ticked, to a great extent, the option that children in age-homogeneous groups have the opportunity to compete with one another. On the other hand, when specifying disadvantages of age-homogeneous groups, precisely the option prevailed that preference is given to competition and mutual comparison of children, thus many teachers perceived this as a negative phenomenon. In pre-primary education there is the trend to create an environment of co-operation rather than competition and children are not to be compared with one another, but in terms of the progress every child makes in comparison with himself/herself. Hence, when forming age-heterogeneous groups, we recommend to include, if possible, a sufficient number of older children (of both sexes) to interact with children of the same as well as younger age.

The research also confirmed that the younger respondents preferred age-homogeneous groups more than the older respondents. As a rule, teachers' age is con-

\footnotetext{
${ }^{4}$ Our research sample consisted of respondents willing to participate in the research, which allows for only limited generalization of the results.
} 
nected with the number of years of their teaching experience. Teachers with more years of experience have more experience and are able to appreciate the advantages brought by the division of children into age-heterogeneous groups. It is possible that, in their studies and shorter teaching experience, younger respondents have had no opportunity to learn about many advantages of age-heterogeneous group formation. Based on the above, it can be recommended that this issue is covered to a greater extent in university studies in pre-primary and elementary pedagogy, especially within the study of kindergarten didactics. Also, students should be given the opportunity within their teaching practice to experience work in an age-homogeneous as well as heterogeneous group and discuss with the teacher trainer the advantages and disadvantages of work in these groups.

\section{Conclusion}

The presented study shows that it is necessary to pay attention to the issue of inclusion of children in kindergarten classes in terms of age and to take note of recommendations of experts in the issue. It followed from the research that the kindergarten teachers who gave their opinion in the questionnaire and interview still preferred age-homogeneous groups. The teachers believed that children develop socially and emotionally better but cognitively worse in age-heterogeneous groups, which was the reason for their preference of age-homogeneous groups.

The research results are an incentive for us to continue the study of the issue and for its inclusion in secondary and university studies in pre-primary and elementary pedagogy. We assume that if kindergarten teachers are aware of the advantages brought by the division of children into age-heterogeneous classes, they will find it worthwhile in spite of its more challenging organization and preparation for education.

\section{Acknowledgement}

The contribution is issued as part of the project KEGA No. $032 \mathrm{KU}-4 / 2016$ "Promoting inclusive education at the pre-primary and primary levels of the school system with an emphasis on socially disadvantaged groups". 


\section{References}

A guide for ensuring inclusion and equity in education. (2013). Paris: UNESCO. Retrieved 12/02/2018, from http://unesdoc.unesco.org/images/0024/002482/248254e.pdf

Blyznyuk, T. \& Sydoriv, S. (2017). Ensuring the Personality-centred Approach in Inclusive Edcation. Scientific Bulletin of Chelm - Section of Pedagogy, 1, 2017, 33-43.

Questionnaire. Available on: https://docs.google.com/forms/d/e/1FAIpQLScEUezpWjX5d-Z_cZKjk6c81P2J9m_b3NTYlsddGuiQRxARwg/viewform

Early Childhood Education and Care Systems in Europe. 2015. [online] Brussels : European Commission/EACEA/Eurydice. Retrieved 30/11/2017, from

http://eacea.ec.europa.eu/education/eurydice/documents/thematic_reports/191EN.pdf

Gray, P. \& Feldman, J. (1997). Patterns of age mixing and gender mixing among children and Adolescents at an ungraded Democratic school. Merrill-Palmer Quarterly, 43, 67-86.

Gray, P. \& Feldman, J. (2004). Playing in the Zone of Proximal Development: Qualities of Self-Directed Age Mixing Between Adolescents and Young Children at a Democratic School. American Journal of Education, 110, 108-145.

Gray, P. (2008) The value of age-mixed play. Education Week, April 16, 2008. Retrieved 10/10/2017, from evolution.binghamton.edu/evos/wp-content/uploads/2008/11/ ValueAge-MixedPlay.doc

Gray, P. (2013). Free to Learn: Why Unleashing the Instinct to Play Will Make Our Children Happier, More Self-Reliant, and Better Students for Life. Philadelphia: Basic Books.

Greenberg, D. (1992). Sudbury Valley's secret weapon: Allowing people of different ages to mix freely at school. In D. Greenberg (Ed.), The Sudbury Valley School experience, $3^{\text {rd }}$ ed. Framingham, MA: Sudbury Valley School Press.

Kaleja, M. (2016). Czech Teachers and Inclusive Primary Education. Journal of International Scientific Publications, 14, 2016, 72-82.

Matejcek, Z. (2015). What Children Need the Most. Praha: Portál.

Montessori, M. (2004). The Discovery of the Child. Revised and Enlarged Edition of the Montessori Method. Delhi: Aakar Books.

Neil, A.S. (1995). Summerhill School. A New View of Childhood. New York: St. Martin's Press.

School for all. Experiences of municipal public schools with inclusion of students with disabilities, ASD, GDD and high ability/giftedness. (2017). Paris: UNESCO. Retrieved 18/01/2018, from http://unesdoc.unesco.org/images/0025/002513/251304E.pdf

Vančíková, K. \& Porubský, Š. \& Kosová, B. (2017). Inkluzívne vzdelávanie - dilemy a perspektívy. Banská Bystrica: Pedagogická Fakulta UMB v Banskej Bystrici, Belianum.

(Inclusive Education - Dilemmas and Perspectives). Banská Bystrica: Faculty of Education, Matej Bel University in Banská Bystrica, Belianum).

Vygotsky, L.S. (1956). Izbrannyje psichologičeskije issledovanija. Moskva: APN.

Decree of the Ministry of Education of the Slovak Republic of 15 July, 2009, amending the Decree No. 306/2008 Coll. of the Ministry of Education of the Slovak Republic on kindergartens. 